\title{
Emergencia protestante y disidencia religiosa en Chiapas
}

\author{
Rodolfo Casillas R. \\ El Colegio de México
}

\begin{abstract}
Resumen
Chiapas es una entidad con viejos problemas de tenencia de la tierra y de antidemocracia, con grupos de poder cerrados, para quienes una modernización capitalista es una especie de socialismo disfrazado. Desde esta óptica, las expresiones religiosas de los conflictos sociales internos se presentan como producto exclusivo de las diferencias confesionales; al desarticular la discrepancia religiosa, de paso se pretende desarticular la inconformidad social. El objetivo de este ensayo es desarrollar algunos elementos, tanto empíricos como de reflexión que respondan a las fuertes interrogantes surgidas ante la emergencia de diversas sectas protestantes y su influencia negativa o positiva, en medio de estas comunidades. Lo que ocurre actualmente con algunos organismos confesionales reclama un estudio serio e inmediato, general y de investigaciones de caso y se espera que la sociedad genere nuevas condiciones que garanticen la tolerancia social y la preservación de los derechos fundamentales de los mexicanos y residentes en el país.
\end{abstract}

Palabras clave: sectas protestantes, capitalismo, modernización capitalista, disidencia religiosa, conflicto político-religioso.

\begin{abstract}
Chiapas has been a state that has suffered from old problems of land ownership and antidemocracy. It also has closed groups of power, for whom capitalist modernization is a kind of disguised socialism. From this point of view, religious expressions of internal social conflicts appear as exclusive product of confessional differences. By dismantling religious discrepancies, they try to erase social disapproval. The objective of this essay is to develop some reflection and empirical elements that may be the answer to strong questionings that appeared in front of the diverse Protestant sects, and the negative and positive influence they have on these communities. Events currently developing at some confessional organisms need an immediate, general, and serious research, using one research for each case. It is expected that society may create new conditions to guarantee social tolerance as well as to preserve fundamental rights of the Mexican people and legal residents in Mexico.
\end{abstract}

Keywords: Protestant sects, capitalism, capitalist modernization, religious dissidence, politicalreligious conflict, Mexican Catholic church. 


\title{
EMERGENCIA PROTESTANTE Y DISIDENCIA RELIGIOSA EN CHIAPAS
}

\author{
por \\ Rodolfo Casillas R.*
}

\section{INTRODUCCION}

En la sociedad mexicana predomina, en materia religiosa, el catolicismo. Este es un hecho constatable que ni los oponentes al catolicismo refutan; sin embargo, en los últimos años se ha presentado un señalamiento recurrente: la presencia y la actividad creciente de las organizaciones protestantes y de grupos disidentes, algunos no cristianos (Véase Bastián 1983 y 1986). Dicho señalamiento por lo regular se presenta en la prensa nacional y, también por lo regular, se menciona el nombre de la organización confesional que se critica. Empero, en todo ello hay un factor común: la descalificación poco menos que indiscriminada, particularmente porque a todas ellas se les da el nombre de "secta", que hoy en día tiene una indudable carga peyorativa. De esta suerte, hay una condena implícita y una descalificación social y religiosa por igual para las iglesias protestantes y para los grupos disidentes no protestantes. Esto hace muy poco favor al análisis y al conocimiento, pues vuelve nebulosa una problemática social ya de por sí difícil de aprehender, debido, entre otras razones, a sus características de pluralidad, complejidad, atomización y de reciente constitución de objeto social de estudio.

No obstante lo anterior, en la crítica hay un reconocimiento no dicho: al señalar el crecimiento de las organizaciones protestantes y noprotestantes en una sociedad predominantemente católica, se está afirmando que aquellas organizaciones están teniendo éxito en su misión proselitista, independientemente de sus fines últimos. En materia religiosa, esto es un problema que afecta a la iglesia católica en su conjunto, pues se rompe el campo simbólico de la religión cristiana que en México monopolizaba (o pretendía hacerlo) dicha organización católica.

En otro nivel de análisis, la acción de las mencionadas organi-

\footnotetext{
* Maestro en Historia, investigador de El Colegio de México.
} 
zaciones protestantes y grupos disidentes no protestantes puede $\mathrm{c}(\mathrm{\prime \prime}$ vertirse en objeto de preocupación del Estado, en la medida en (qu afecte el orden social establecido -se entiende que la afectación s'i" disfuncional al Estado. Con esto se quiere decir que no necesariı mente la acción que atenta al campo religioso atenta de igual mancra al campo social, se puede romper el primero sin afectar al segundo; dv ser así, habrá razones para que la iglesia católica actúe, pero no cl Estado mexicano. Cuando una acción afecte tanto al campo religioso como al orden social establecido, sin duda habrá reacción de la iglesia católica y del Estado; pero no necesariamente tendrá que ser una respuesta concertada. Cada cual podrá responder de acuerdo con sus medios y a la dimensión que le signifique la acción a la que responde. También puede que sea una respuesta concertada; ello dependerá de la evaluación que en un momento específico hagan la iglesia católici y el Estado y en que convengan actuar de una manera determinada. No siempre será posible, necesario o pertinente, que la iglesia católiciı y el Estado actúen de manera conjunta frente a los distintos desafíos que puedan presentar las organizaciones confesionales no católicas.

Estamos frente a un panorama complejo que es necesario dilucidar, en el cual afloran interrogantes como las siguientes: ¿son todas las organizaciones protestantes y grupos disidentes no protestantes iguales, religiosa y socialmente hablando?, el crecimiento y cl éxito que se mencionan ison comunes a todas, cuáles sí crecen y triunfan y cuáles no y por qué?, particularmente ien qué rompen el espacio simbólico de la religión y con cuáles medios?, ise preocupa la iglesia católica porque se le cuestiona su liderazgo religioso, "su verdad" religiosa exclusivamente, o también porque se atenta contra su incidencia social?, y si hay algo de cierto en esto último ¿dónde queda el espíritu ecuménico?, ¿en qué y cómo, de ser el caso, atentan dichas organizaciones confesionales al orden establecido?, icuenta el Estado con un marco legal apropiado para hacer frente a los eventuales conflictos que dichas organizaciones puedan crearle?, ¿qué hay que hacer, en todo caso, para no caer en la dinámica de los intereses constituidos que eventualmente puedan responder a directrices particulares, sean internas y/o externas, y que se yuxtapongan a determinados espacios sociales en provecho particular?, etc. Es obvio que en este ensayo no se pretende dar respuesta a todas las preguntas planteadas. Lo que se propone es desarrollar algunos elementos, tanto empíricos como de reflexión, que se espera contribuyan a responderlas. 


\section{Un punto de partida: ¿dónde estamos?}

Fuera de las instituciones confesionales, las instancias de investigación social en el país no se avocan al estudio de lo religioso; para decirlo de corrido, la sociología de la religión no existe en el país, sólo uno que otro investigador, desde la ciencia política, la antropología o la historia, se aventura a discurrir sobre el tema, más con buena intención e interés intelectual que con una formación sólida en la materia. De ahí, con toda certeza, las posibles limitaciones que existen en este tipo de estudios -entre los cuales debe ubicarse el presente. Si históricamente hablando la iglesia católica ha sido la referencia obligada cuando se discute de religión en este país, y de ella se sabe poco en la actualidad, como sociedad todavía estamos lejos de tener una idea clara de lo que las organizaciones confesionales no católicas han sido, son y pueden significar en nuestra vida nacional. De esas organizaciones sabemos poco, casi nada, en particular de los protestantes y de los grupos disidentes no protestantes, casi se podría decir que se sabe más de lo que los descalifica que de lo que los califica de manera positiva. En pocas palabras, que hay más ideología que conocimiento concreto.

La iglesia católica también fue la referencia obligada cuando se legisló en México sobre materia religiosa, y aun lo es cuando se introducen modificaciones a los procesos electorales en el país. Aunque se reconoce que no se cuenta con una base de sustentación sólida, se plantea la hipótesis de que la legislación mexicana no contempla la actividad de las organizaciones protestantes y de los grupos disidentes no protestantes. Puede que las contemple en lo sustancial, pero hay aspectos que escapan a la legislación porque ésta tiene de referencia las formas organizativas y materiales de la iglesia católica. Un ejemplo de ello es el siguiente: el artículo 130 de la Constitución señala que "Para dedicar al culto nuevos locales abiertos al público se necesita permiso de la Secretaría de Gobernación, oyendo previamente al gobierno del Estado" (Constitución 1987: 119).

No se pone en duda que en la mayoría de los casos, tanto la iglesia católica como las iglesias y organizaciones protestantes históricas (es decir, de la Reforma) sí respeten la norma constitucional; pero es de dudar que cientos y cientos de casas particulares, pequeños y 
humildes locales y otras construcciones menores, de un buen número de sectas y organismos no protestantes, hayan seguido el proceso constitucional y en consecuencia formen parte del patrimonio nacional. De igual manera, tal vez no se respete lo concerniente a lo estatuido en el mismo artículo sobre el encargado de cada local, de los registros al día que debe llevar la autoridad municipal, de que se apliquen las sanciones de destitución y multa a las autoridades que incumplan la norma constitucional del artículo 130. Por otra parte, el hecho de que el Estado mexicano esté financiando algunas investigaciones académicas sobre la sectas protestantes y grupos disidentes no protestantes, puede deberse a que, políticamente, le sca más conveniente y menos susceptible de conflicto con autoridades estatales y municipales, proveerse de la información necesaria que les permita adoptar una postura determinada. Esto que puede entenderse como una prueba de tacto político, también puede ser muestra de que se duda que, legalmente, el instrumental con que sc cuenta sea apropiado. De no tenerlo, este vacío legal facilita cl crecimiento y la actividad de dichas organizaciones confesionales, tanto en lo social como en lo religioso. Si después de informarse, el Estado considera que su actividad afecta negativamente el orden establecido, tendrá que crear el marcojurídico correspondiente a fin de que su acción sea legal; de no hacerlo, su represalia podrá ser sumada a la crítica que lo califica de represor, ilegal, autoritario, que no respeta la pluralidad de pensamiento y de creencia. En pocas palabras, se hablará de más antidemocracia. Pero mientras tanto, cabe preguntarse por qué el Estado no recurre a lo que tiene a la mano. Quizá la respuesta es muy simple: para el Estado la actividad social de esas organizaciones confesionales no ha puesto en peligro el orden social establecido y, por lo tanto, no ha tenido que actuar con energía. Es posible que lo atomizado de estas organizaciones contribuya a verlas como un peligro menor, de efecto local, focalizado, aislado y aislable, sin dimensión nacional; empero, su creciente incidencia social ha llamado la atención estatal y al parecer, se está en vías de darle otra dimensión social y de diferenciación de campos de competencia del Estado y de las organizaciones confesionales.

Para decirlo coloquialmente, la iglesia católica, por tener interés de parte, no es del todo objetiva; son pocos los señalamientos públicos de autocrítica, en donde se reconoce que el crecimiento de las organizaciones protestantes y de disidentes no protestantes se debe, en gran 
parte, a los errores y equívocos que la propia iglesia católica ha cometido. Han menudeado las críticas y las condenas, los llamados al Estado para que actúe contra ellas, pues son instrumentos de imperialismo que atentan contra los valores y símbolos nacionales y que, además, aculturan a las minorías étnicas del país, con las consecuentes pérdidas de las culturas tradicionales. Independientemente de la validez o no, relativa o absoluta, que puedan tener los señalamientos alarmantes que han hecho tanto miembros del alto como del bajo clero católico, da la impresión de que al mezclar los campos político y religioso y al llamar más a la acción del Estado, se está cayendo en un grave error.

En primer lugar, si se reclama mayor autoridad estatal con respecto a determinados grupos confesionales, poca autoridad moral queda cuando el Estado mismo aplique una política de control estricto, igualmente válida para todas aquellas organizaciones y personas religiosas que incursionen en la vida sociopolítica; desde esta perspectiva, la iglesia católica como institución tiene mucho que perder, con más razón ahora que se considera con mayor fuerza social para reclamar una personalidad jurídica y legal, con plenos derechos para ella y sus miembros regulares. En segundo lugar, esa indiferenciación de campos no le permite avanzar en la solución de los problemas que realmente le competen, tanto en los de conflicto como en los de comunión ecuménica. Metodológicamente, me parece que a la iglesia católica le será muy difícil avanzar en la evaluación crítica de sus comportamientos, instrumentos, compromisos, concepciones, etc., si no diferencia para distinguir, es decir, darle vida al lema cristiano de "distinguir para unir"; también podemos agregar: para separar lo que no es ni lleva a la unidad. En tercer lugar, al hacer una evaluación incorrecta, productode una indiferenciación que nopermite llegar a los pesos específicos, no puede dar una orientación verdadera a sus fieles; éstos, al no tener la respuesta debida, con mayor facilidad pueden convertirse al protestantismo, o pasar a engrosar las filas de otros grupos cristianos no católicos, o perder la fe. Estos peligros no son del todo potenciales, el crecimiento poblacional de los grupos cristianos no católicos se ha dado con personas anteriormente católicas; es decir, se habla de un peligro real, actual, que no por ser sólo uno se le debe menospreciar, en todo caso hay que darle su peso específico, y para hacerlo, hay que diferenciar. Al hacerlo, la iglesia católica podrá, con mayor conocimiento de causa, establecer y ejecutar sus doctrinas 
políticas con respecto al Estado, a las otras organizaciones cristianas, con sus fieles, con sus compromisos de identidad nacional, sin buscar abrigos gubernamentales que le puedan resultar contraproducentes, etc., de una manera más pertinente y acorde a la realidad social del momento.

Como ya se ha dicho, la prensa de circulación nacional ha incrementado su número de notas y noticias en los últimos años con respecto a las actividades de las organizaciones religiosas, en particular sobre las protestantes y grupos disidentes no protestantes. También ya ha sido señalado que una característica común a ese material publicado es su énfasis en los aspectos negativos de las actividades realizadas por dichas organizaciones confesionales. Falta, quizá en los artículos de fondo, una evaluación crítica de las noticias y reportajes que los mismos diarios presentan sobre esas organizaciones, en donde se consideren otros elementos de juicio, a fin de presentar un análisis objetivo, mesurado, que realmente contribuya a informar y formar opinión, reduciendo en consecuencia el espacio a un eventual alarmismo.

Luego de este rápido recorrido, podemos concluir que en la sociedad mexicana, en sus instituciones gubernamentales, de reflexión académica, de información pública y confesional católica ${ }^{1}$, se cuenta con un conocimiento sobre las organizaciones protestantes y grupos disidentes no protestantes que se caracteriza por ser: parcial, descalificador, generalmente en muchos casos prejuiciado, indiferenciador, generalmente ideologizado, etc. Si este tipo de conocimiento es el que llega al ciudadano común ${ }^{2}$, no debiera extrañar su

1 Faltaría presentar el punto de vista de las iglesias protestantes para tener un cuadro más completo. Hasta cierto punto, ellas son las primeras interesadas en distinguirse de las organizaciones disidentes e incluso no cristianas. Empero, por sus reacciones públicas sobre el particular, que han sido por demás pobres y de limitada circulación, se puede inferirque lo principal de su aportación está por darse, religiosa y socialmente hablando. Esto es, al parecer no han encontrado la forma de participar en la discusión; parece que son mayores los impedimentos, ya que los temores ancestrales son un obstáculo para que ellas tengan un papel central en la polémica.

${ }^{2}$ Por ciudadano común he querido decir católico, en tanto que es parte de la base poblacional nominalmente mayoritaria en el país. Ello, como se verá en las líneas por venir, se sustenta no sóloen su mayoría numérica sino fundamentalmente en su mayor exposición a la labor misionera de las nuevas organizaciones religiosas energentes en la sociedad mexicana. 
intolerancia religiosa y social, que no sólo queda en el cartelito en la puerta o ventana que da a la calle que dice "este hogar es católico, no se admite propaganda protestante", sino que incluso conduce a ver con recelo y desconfianza a los propios católicos que se apartan de la ortodoxia en la realización de su compromiso de fe en esta vida. De igual manera, si este tipo de conocimiento forma parte del bagaje que cualquier cristiano no católico recibe en su trato social, no debiera extrañar que el descalificado descalifique, que el intolerado se vuelva intolerante, hasta llegar a una intolerancia mutua y plenamente correspondida con los católicos, situación que en nada beneficia a la convivencia social ni al más noble de los ecumenismos. Al ciudadano común, pero particularmente al fiel cristiano, sólo le ha quedado su existencia cotidiana como la única forma de mantener su creencia dentro de una organización, ode convertirse a otra expresión cristiana, o dejar de creer.

Para muestra un botón: algo sobre las diferencias religiosas en Chiapas

Antes que nada se presentan las premisas de las que parto: 1) aunque reconozco que algunas organizaciones protestantes y grupos disidentes no protestantes pueden tener patrocinadores y/o fuentes de apoyo financiero externo, pienso que su acción no tendría éxito si no hubieran condiciones internas que les favorecieran; es decir, su presencia y actividad crecientes se explicarían, fundamental y principalmente, por el acontecer doméstico y, de manera subordinada, por los elementos externos. 2) Cuandose reducen ono existen posibilidades de dar cauce por medios legales a las expresiones populares, la religión se convierte en el vehículo de ellas. Para decirlo con Gramsci, "frente al control del aparato político, el aparato religioso se convierte en el modo esencial de expresión de los grupos subalternos" (Portelli, 1977). 3) En Chiapas, los espacios y las vías legales de expresión de inconformidad social, política y económica de los grupos subalternos han sido de facto reducidos a su mínima expresión por los grupos de poder local y regional en la entidad. 4) Los compromisos que históricamente ha contraído la iglesia católica ${ }^{3}$ con dichos grupos de

\footnotetext{
${ }^{3} \mathrm{Al}$ hablar de los compromisos históricos de la iglesia católica, no desconozco los importantes cambios en la cosmovisión y práctica pastoral de algunos miembros de la estructura eclesiástica, entre ellos el obispo Samuel Ruiz. No obstante, éstos han sido la excepción y no el comportamiento ordinario institucional.
} 
poder para la preservación del status quo, la inhiben para que se convierta en el vehículo por excelencia para dar cauce de expresión a la inconformidad popular. 5) Ante la creciente inconformidad social, la llegada y actividad de organizaciones protestantes y grupos disidentes no protestantes ocurrida durante los últimos años, han constituido, al menos a corto plazo, la posiblidad de paliar, si no es que la firme convicción de solucionar, sea en este mundo o en el otro, los sufrimientos del hombre. En las siguientes páginas se presentan algunos datos empíricos que le dan cuerpo a las premisas antes escritas, ${ }^{4}$ enfatizando más algunos aspectos que otros; ciertamente que se hará en los que resultan más pertinentes para esta discusión y en aquéllos sobre los cuales se dispone de información suficiente. Fuera de los censos y del ejercicio que con ellos se hace, los datos numéricos que se utilizan no son representativos de toda la problemática religiosa en Chiapas, mucho menos constituye un censo de ellas, pero pueden arrojar algunas luces que iluminen.

Para no hacer un ejercicio largo que pueda ser tedioso, se consultan sólo los datos de los censos nacionales de población de México en materia de religión para el estado de Chiapas de los años 1960, 1970 y 1980. De los rubros que presentan los censos se utilizaron los correspondientes a "Total de la población", "Católica", "Protestante" y "Ninguna"; por ser los más significativos al análisis. Los restantes: "Judáica", "Otras" y "No específica", se excluyen por su bajo valor numérico y porcentual, así como por noafectar sustancialmente la línca de análisis que aquí se sigue. Veamos, en consecuencia, el cuadro 1.

Los datos censales indican que en 1960 la población de Chiapas era predominantemente católica $(92.7 \%)$, seguida de lejos por la protestante $(4.2 \%)$ y todavía más lejos estaba la que declaró no tener religión alguna $(0.9 \%)$; sin embargo, para el decenio siguiente, la población que se declaró católica sufre una baja en términos porcen-

${ }^{4}$ Importan las siguientes aclaraciones: ciertamente, el sustentar cada una de las premisas requiere, en el mejor de los casos, un buen número de cuartillas y, en conjunto, todas ellas reclaman una larga investigación que ni tengo hecha ni la voy a hacer en este escrito. En todo caso, mis visitas previas a Chiapas, entrevistas con gente de la región, sistematización de datos cuantificables, mis estudios sobre el árca chiapaneca y la posibilidad de discutir con investigadores sociales de aquellas ticrras, me permiten presentar estas reflexiones que tienen una buena dosis hipotética, y como tales, sujetas a rectificación. 
CUADRO 1. Distribución de la población de Chiapas según religión 1960-1980

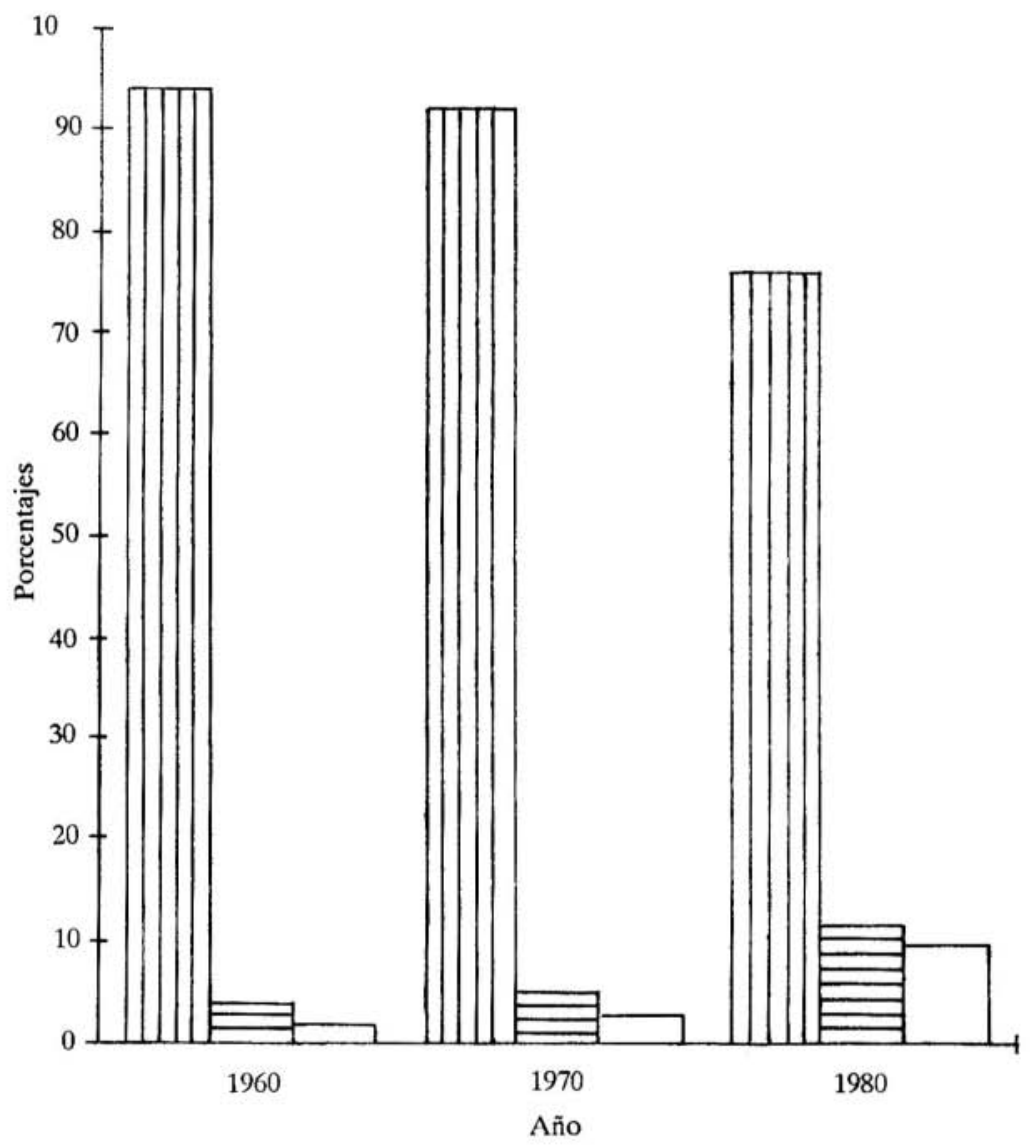

WII Católica

E Protestante

$\square$ Sin religión 
tuales con relación al total de la población registrada en la entidad, pues sólo alcanzó un $91.2 \%$. De cualquier modo, podría decirse que liı religión católica sigue predominando, máxime que en los mismos términos porcentuales los protestantes lograron un avance de 6 décimas: $4.8 \%$ para 1970 . En cambio, la población que no profesi religión alguna presenta un cambio muy notorio, de $0.9 \%$ del decenio anterior pasa a 3.5\%. Ya para 1980 hay cambios importantes en todos los sentidos: los católicos alcanzan un $76.9 \%$ que, con respecto del $91.2 \%$ de 1970 , sufren una pérdida de $14.3 \%$ y presentan una baja de un $15.8 \%$ con respecto del $92.7 \%$ de 1960 . En pocas palabras, la proporción de la población católica se está reduciendo, particularmente de 1970 a 1980 sufre una contracción muy fuerte. Por su parte, la población protestante en el último censo nacional se apunta un $11.5 \%$ que, comparado con lo obtenido 10 años atrás, se anota un incremento de $6.7 \%$ y un incremento mayor $(7.3 \%)$ con respecto de la cifra de 1960 . Es decir, la base poblacional protestante se amplía, crecimiento relativamente modesto de 1960 a 1970, pero con un crecimiento impresionante de 1970 a 1980 . En lo que respecta a la población sin religión, para 1980 el porcentaje obtenido es de $10 \%$, $6.5 \%$ más que en 1970 y $9.1 \%$ más que en 1960. La conclusión es obvia: crecimiento ininterrumpido y constante de la población sin ninguna religión. Lo antes dicho se presenta en la gráfica 1.

Ciertamente, se podría argumentar que las conclusiones anteriores son parciales y pueden dar lugar a una lectura equivocada, pues en el período de referencia hay crecimientos absolutos tanto de la población total como de la población católica, protestante y sin ninguna religión. En efecto, las conclusiones anteriores son parciales y para evitar equívocos es pertinente hacer dos aclaraciones: 1) al presentarlas, lo que interesa es llamar la atención sobre los cambios en la proporción que presentan cada una de las poblaciones católica, protestante y ninguna religión. 2) Estas verdades parciales al ser relacionadas con otros elementos de análisis, cosa que se realizará más adelante, ganarán más objetividad y confiabilidad.

Veamos ahora el porcentaje de crecimiento sobre sí mismas que tienen las poblaciones católica, protestante y sin religión. Para efectos de este ejercicio, como se observa en el cuadro2,1960 será igual a $100 \%$. 
CUADRO 2. Porcentajes de crecimicnto en poblaciones de referencia 1960-1980.*

\begin{tabular}{lccc}
\hline Año & $\begin{array}{c}\text { Población } \\
\text { católica }\end{array}$ & $\begin{array}{c}\text { Población } \\
\text { protestante }\end{array}$ & $\begin{array}{c}\text { Población } \\
\text { sin religión }\end{array}$ \\
\hline 1960 & 100.0 & 100.0 & 100.0 \\
1970 & 127.5 & 148.2 & 509.0 \\
1980 & 142.7 & 470.0 & $1,907.0$ \\
\hline
\end{tabular}

Fuente: VIIICenso General de Población y Vivienda. Dirección de Estadística, Secretaría de Industria y Comercio, México. 1964.

IX Censo General de Población. Dirección General de Estadística, Secretaría de Industria y Comercio, México. 1971.

X Censo General de Población y Vivienda. Instituto Nacional de Estadística, Geografía e Informática, Secretaría de Programación y Presupuesto, México. 1984.

* Cálculos del autor

Para no abusar de los números ni cansar al lector, se anota una verdad sencilla y también parcial: las poblaciones consideradas incrementaron su porcentaje de crecimiento sobre sí mismas, pero la católica fue la que menos lo hizo, la población sin religión fue la que más incremento tuvo, dejando muy atrás a la católica. Por su parte, la protestante tuvo un porcentaje de crecimiento en todo momento superior al correspondiente a la católica, aunque superado también en todo momento por los índices de crecimiento de la población sin religión. Pero, a diferencia de lo ocurrido con la católica, la brecha entre protestantes y sin ninguna religión no es tan contundente, mas no por ello pierde relevancia analítica; esto es, se puede hablar, así sea a nivel hipotético, no sólo de una división creciente del campo simbólico de la religión, sino incluso de una eventual reducción del mismo.

Toca turno a las tasas de crecimiento de la población según su religión. Primero las de crecimiento medio anual, en el cuadro 3. 
CUADRO 3. Tasas de crecimiento medio anual de la población en Chiapas según religión 1960-1980.*

\begin{tabular}{lcccc}
\hline Año & $\begin{array}{c}\text { Población } \\
\text { total }\end{array}$ & $\begin{array}{c}\text { Población } \\
\text { católica }\end{array}$ & $\begin{array}{c}\text { Población } \\
\text { protestante }\end{array}$ & $\begin{array}{c}\text { Población } \\
\text { sin religión }\end{array}$ \\
\hline $1960-70$ & 2.60 & 2.46 & 4.01 & 17.70 \\
$1970-80$ & 2.88 & 1.14 & 12.20 & 14.10 \\
\hline
\end{tabular}

Fuente: VIII Censo General de Población y Vivienda. Dirección General de Estadística, Secretaría de Industria y Comercio, México. 1964.

IX Censo General de Población. Dirección General de Estadística, Secretaría de Industria y Comercio, México. 1971.

X Censo General de Población y Vivienda. Instituto Nacional de Estadística, Geografía e Informática, Secretaría de Programación y Presupuesto, México. 1984.

* Cálculos del autor.

Las cifras son por demás elocuentes, la tasa de crecimiento de la población católica fue siempre a la zaga, casi duplicada por la protestante y dejada de calle por la correspondiente a la población sin religión entre 1960-70. Para 1970-80, la cuestión se complica para la población católica, pues sufre una baja en la tasa de crecimiento medio anual de poco más de la mitad de la ya de por símínima tasa de 196070. Ello ocurre frente al disparo en la tasa de la protestante que se triplica, y de un modesto crecimiento en la tasa de población sin religión; crecimiento modesto que no por serlo, deja de confirmar que está dejando de calle el crecimiento relativo de la población católica.

Por último, veamos la tasa de crecimiento medio de la población total.Si comparamos estas tasas con las anotadas en el párrafo anterior, tenemos losiguiente: para 1960-70 la tasa de crecimiento medio anual de la población católica casi estuvo a la par con la de crecimiento medio de la población total, $2.46 \%$ y $2.6 \%$ respectivamente; empero, la tasa de crecimiento protestante, que fue de $4.01 \%$, casi puede decirse que duplica la tasa de crecimiento medio de la población total.Por su parte, la tasa correspondiente a la población sin ninguna religión, de $17.7 \%$, 
supera con creces la tasa de crecimiento medio de dicha población total. Ahora, si para 1960-70 observamos en conjunto las tasas de crecimiento de la población católica $(2.46 \%)$, protestante $(4.01 \%)$ y ninguna religión $(17.7 \%)$, frente a la tasa de crecimiento medio de la población total (2.6\%), tendremos que lo logrado por la población protestante es prácticamente el doble de la obtenida por la católica, perolo logrado por la población sin religión deja muy atrás el logro protestante y, todavía más atrás, el católico.

Veamos ahora el período 1970-80 usando el mismo análisis comparativo de tasas de crecimiento. La tasa de crecimiento medio de la población total para dicho período fue de $2.88 \%$, como quedó señalado en el cuadro anterior, y también como ya se señaló antes, la tasa de crecimiento medio anual católica fue, para 1960-80, de $1.14 \%$, la protestante de $12.2 \%$ y la población sin religión de $14.1 \%$. Se observa que la tasa de crecimiento de la población católica también disminuye en poco más de la mitad con respecto de la tasa de crecimiento medio de la población total de Chiapas. Si en el período 60-70 se mantuvo casi a la par, en 70-80 definitivamente no aguantó el paso. La tasa correspondiente a la población protestante, en cambio, se dispara al alza. Si en 60-70 la tasa de crecimiento protestante duplicó la tasa de crecimiento de la población chiapaneca, para 70-80 de hecho la cuadriplicó. La tasa de población sin religión también se mantuvo al alza. Si en el período 60-70 octoplicó la tasa de crecimiento de la población total, para 70-80 sólo quintuplicó dicha tasa de población. En todo caso, se observa un fuerte reflujo católico y un impresionante crecimiento de protestantes y de población sin religión. El razonamiento se visualiza de mejor manera en la gráfica 2 .

Luego de hacer este necesario ejercicio de cálculos porcentuales y de tasas de crecimiento, puede afirmarse sin remilgo alguno que la iglesia católica está pasando por un mal momento en Chiapas; que está perdiendo su base poblacional, que su crecimiento no se mantiene ni siquiera acorde con el ritmo de crecimiento de la población y ello, hay que reconocerlo, no es necesariamente producto de la obra de los protestantes. Recuérdese, en todo caso, que los crecimientos más significativos se dan en la población sin religión. Llama la atención el crecimiento de la base poblacional aglutinada bajo el rubro de protestantes, sobre todo en el período 70-80. Esta conclusión confirma el reiterado señalamiento que se ha hecho, particularmente en la 
CUADRO 2. Tasas de crecimiento medio de la población de Chiapas según religión 1960-1980.

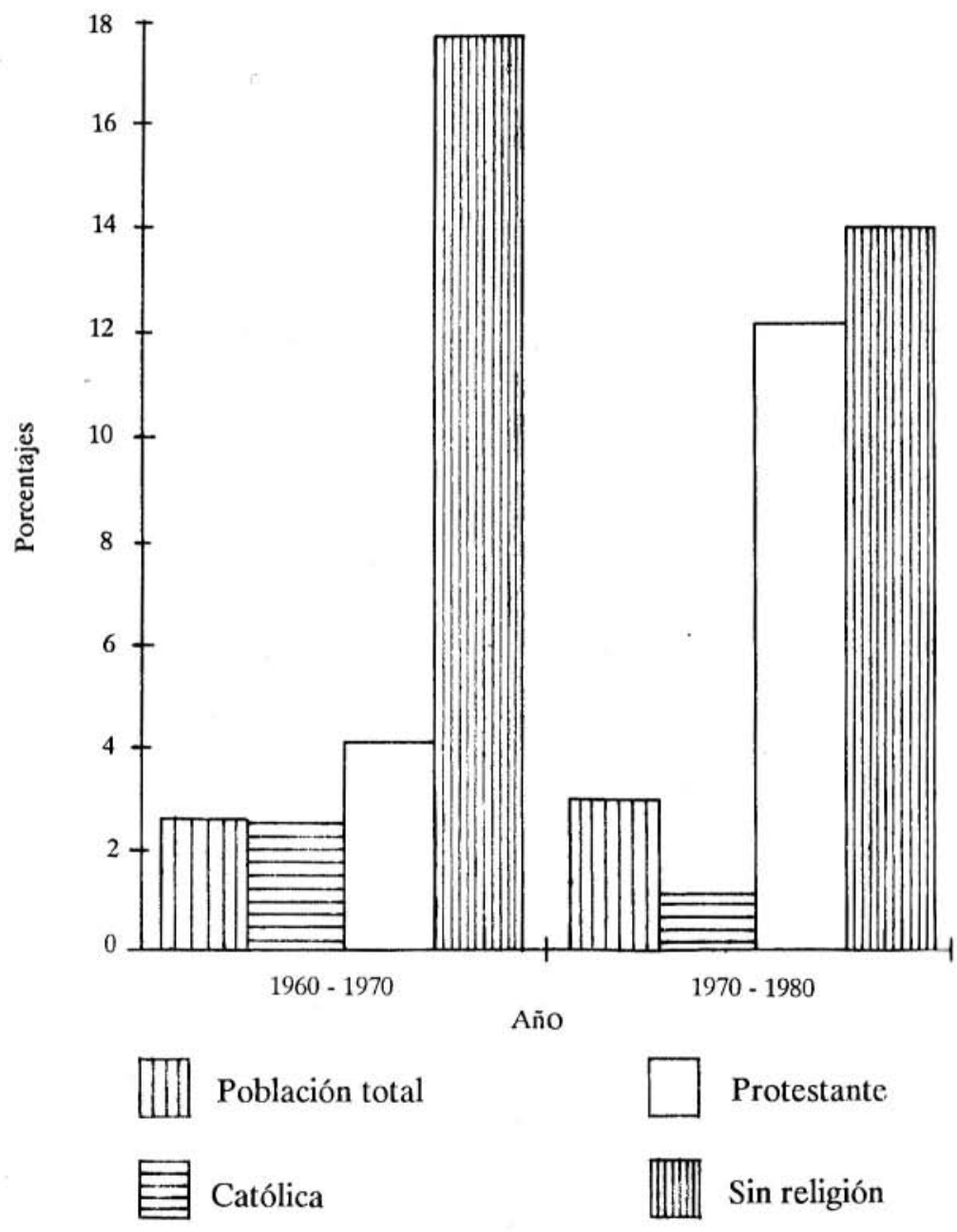


prensa, acerca de dicho crecimiento, aunque cabe aclarar que los datos del censo no permiten distinciones entre organizaciones protestantes y grupos disidentes no protestantes -a los cuales se hará referencia en las páginas siguientes.

Quizá lo más sorpresivo de este ejercicio sea el crecimiento absoluto y relativo, tantoen términos porcentuales como en tasas de crecimiento, de la población sin religión. Este hallazgo debe interesar sin distingos a todos los cristianos, pues de mantenerse lastendencias encontradas, el problema no será tanto de qué tan fraccionado esté el campo religioso yen provecho de quién, sino que la existencia misma de dicho campo está en peligro. Por supuesto que señalar el extremo puede sonar irreal y no es creíble; pero, al menos cautamente, el mundo creyente puede preguntarse por qué crece tan rápidamente en los últimos años, al menos en Chiapas, el número de población que no cree. Visto con seriedad, no cabe caer en simplismos justificatorios del siguiente tenor: si hay menos católicos es por culpa de los protestantes y si hay menos creyentes es por la acción atea del Estado. Al parecer, no sería acertado sostener ninguna de las afirmaciones, pues encuentran supuestos culpables sin aportar explicaciones ni elementos de autocrítica. La cuestión es más compleja y, por tanto, hay que abordarla en su complejidad y no reducirla a esquematismos ideológicos. Para concluir con este párrafo, una última reflexión a propósito de la complejidad de la problemática religiosa que se aborda. El hecho de que se dé una baja en la proporcionalidad poblacional católica y una alza en las correspondientes proporcionalidades protestantes y de población sin reli-gión, noquiere decir necesariamente que lo ocurrido a la primera se deba a las segundas y viceversa. Los censos presentan datos acerca de la población de Chiapas, pero no hay garantía alguna de que se trate de la misma población en 60,70 y 80 . Hay cambios en la composición y número de la población debido a diversos factores, entre los que se puede mencionar, como ejemplo, los movimientos migratorios intraestatales e internacionales. Esto significa que no se descalifican los datos obtenidos ni los análisis realizados, pero sí se les relativiza en función de la incidencia de otros elementos sociales que los censos no proporcionan y que tampoco se obtienen del todo en una investigación social que cubra todo el período, pues en sentido estricto, no se mantiene estática a la población chiapaneca durante 30 años. En consecuecia, la investigación social recurre a ejercicios como el aquí elaborado a fin de establecer tendencias que, a su vez, orienten y permitan establecer ciertas pautas de orientación y acotamiento. Dicho esto, pasaremos a otro nivel de análisis. 
Las visitas de trabajo a Chiapas en los últimos 28 meses, las entrevistas y la colaboración de un grupo de amigos, me permitieron captar algunos de los datos que ahora se presentan ya sistematizados. Le recuerdo al lector que no son representativos de la problemática religiosa en la entidad; a lo más, aspiran a nutrir hipótesis de investigación que, al amparo de las reflexiones antes presentadas, puedan convertirse en un punto de partida de estudios ulteriores.

Los datos censales arrojan como resultado un auge reciente de la población protestante. Los datos disponibles permiten, en principio, estar de acuerdo con la conclusión general, aunque aparte se pueden establecer diferencias; la primera es que, particularmente en el último quinquenio, son los testigos de Jehová los que han cobrado mayor presencia, seguidos por organizaciones adventistas y en tercer sitio, con un fuerte impulso en los dos últimos años, de los grupos pentecostales. También hay actividad de otras denominaciones protestantes y de grupos disidentes no protestantes, pero aquí sólo menciono las que resultaron más recurrentes en la observación y entrevistas. Prácticamente, de las mencionadas se encuentran fieles de ellas tanto en centros urbanos como en alejados caseríos con promedios de 10 familias por localidad. En todos los casos se notó una intensa actividad de dichas organizaciones, tanto hacia su interior como en labores de proselitismoentre las gentes que no formaban partè de su organización. Es decir, la búsqueda de la conversión se hacía indiscriminadamente entre católicos y miembros de otras organizaciones cristianas.

El proselitismo lo hacen 2 o 3 miembros de la organización que, particularmente los domingos, se encaminan a cumplir su misión. Con esto se quiere decir que cualquier miembro de dichas organizaciones hace proselitismo, que no depende de la labor de los pastores o ministros, o de los más doctos en el nuevo testamento, o en el libro del mormón, para mencionar una iglesia no cristiana; van la mayoría de las veces en parejas o toda la familia tocando de puerta en puerta difundiendo su credo particular. En otras ocasiones un grupo más o menos numeroso se congrega en la plaza principal de la localidad y con cantos y discursos llaman a nuevos adeptos; inclusolos más audaces visitan entre semana oficinas y comercios, sin que los desalienten los rechazos y silencios elocuentes. Ciertamente no todos los fieles protestantes y miembros de los grupos disidentes no protestantes actúan de esa manera; pero sí es un rasgo que destaca frente a la discreción y casi 
desapercibida acción de los católicos; de hecho no se encontraron grupos organizados de fieles católicos en campañas similares. Tal parece que se sigue privilegiando el culto externo dominical y de días festivos, las rondas de catecismo para niños comulgantes y para las señoritas, las tardeadas de juventud y los grupos de coros y rondallas, etc., es decir, métodos tradicionales, quizá ya gastados, no renovados ni enriquecidos con otras formas de proselitismo más acordes con los tiempos actuales.

Aunque el "auge protestante" parte de unos años a la fecha, lo cierto es que las bases poblacionales datan de decenios anteriores. Por ejemplo Tapachula, que es un importante centro de difusión y conversión protestante y de disidencia no protestante, cuenta con locales que, según placa alusiva, se fundaron en los años veinte, teniendo al frente pastores con nombre hispano. Esto nos lleva al tema de la nacionalidad. Se plantea la hipótesis de que el grueso de los pastores y ministros, protestantes y de disidencia no protestante, son mexicanos. Se parte de los siguientes elementos: la antigüedad y el número actual de dichas organizaciones les permite contar con personal mexicano al frente de organizaciones locales; incluso las de más reciente presencia pueden reproducir sus cuadros medios mediante la conversión, a través de la labor de fieles que migran a otras tierras y allá difunden o se convierten al credo y al retornar lo diseminan en su lugar de origen. Por otra parte, está la práctica del sacerdocio universal y la existencia de mecanismos bastante flexibles para el nombramiento de pastores, como lo hacen los pentecostales, lo cual no es garantía de que se dé una cierta homogeneidad en el mensaje que se difunde ni la interpretación consecuente que se pueda hacer de lasenseñanzas bíblicas - pero esto últimoconstituye un problema aparte que aquí no se aborda. Otro elemento a considerar es que las organizaciones protestantes y la disidencia no protestante cuidan de no violentar, al menos de no hacerlo burdamente, la parte del artículo 130 constitucional que dice que "para ejercer en México el ministerio de cualquier culto se necesita ser mexicano por nacimiento". Ciertamente en Chiapas, como en otros lugares del país, son fácilmente distinguibles los personajes con presencia sajona, camisa blanca, corbata y biblia bajo el brazo, pero ésos son los menos, llaman más la atención por su presencia que por su número. Aparte, es prácticamente común que religiosos extranjeros, de distintas creencias, ingresen al país bajo diferentes figuras migratorias; familiares de alguien que viene en plan 
de turismo, técnicos, lingüistas, estudiosos de distintas áreas que cn México no hay, o que escasean, etc.; esto les puede hacer más cautos cn su actuar, pues no sólo está en juego la deportación del infractor, sino eventuales sanciones contra la organización confesional a que esa persona pertenece. Acorde con esta línea de razonamiento, para mí quc esa presencia de religiosos extranjeros es baja numéricamente hablando y sus actividades se centran en labores de mínima exposición pública.

Una organización protestante o de disidentes no protestantes crece en su entorno social inmediato. Ya antes se mencionaron algunas prácticas usuales de proselitismo. Chiapas es una entidad predominantemente agraria, son pocas sus grandes ciudades (Tuxtla, San Cristóbal, Tapachula y Comitán) y en sus 110 municipios menudean las poblaciones dispersas, mal y difícilmente comunicadas, en parte debido a la propia geografía chiapaneca. Esto quiere decir que, en términos de proselitismo, la labor no es fácil, por el contrario, es ardua, problemática y puede ser desgastante, física y espiritualmente, para alguien no muy convencido de que debe colaborar en la evangelización; no siempre se puede viajar con comodidades ni es creíble decir que las organizaciones de referencia tienen una infraestructura de comunicación que les haga cómodo y expedito su proselitismo. Es posible que dispongan de algunos vehículos de doble tracción y hasta de avionetas; pero el trabajo cotidiano, el que casi no se ve, se hace a pie y algunos en caballo o burro. Ese trabajo cotidiano lo hace la gente del pueblo y la única manera de constatarlo es internándose en los poblados al atardecer de cualquier día, en ocasiones incluso los sábados, para ver grupos de jóvenes, de adultos, de familias que con un ejemplar de la biblia se encaminan a una localidad vecina para acuảir al servicio religioso. Esto se observó por distintos lugares chiapanecos; no hubo tarde ni camino por que se transitara en que no se encontrara al menos un grupo de fieles o un local de culto cristiano. En cambio, no se encontró este tipo de movilizaciones de católicos, ni tampocoun local para el culto católico en alejados parajes, por humilde que fuera. ${ }^{5}$ Ello nos lleva a pensar que si ese es el comportamiento

5 En honor a la verdad tengo que decir que ciertamente no he recorrido todos los caminos y veredas de Chiapas, pero sí las más transitadas de sus carreteras y algunos de los caminos menores de la región del Soconusco y uno que otro de la región de los Altos. 
general de unos y otros, es posible suponer una situación que se caracteriza por una mayor actividad proselitista de los protestantes y de la disidencia no protestante que, a la luz de los datos proporcionados por los censos aquí utilizados, ayudarían a explicar el porqué del ensanchamiento de las bases poblacionales de dichas organizaciones confesionales. Obviamente el ensanchamiento no es parejo, pero se carece de base empírica para señalar con absoluta precisión cuáles son las organizaciones que más están acrecentando sus filas.

En su labor de proselitismo religioso los protestantes y los disidentes no protestantes recurren al uso de los medios de comunicación masiva; también lo hacen los católicos, pero me atrevo a decir que con menores resultados. Con base en las entrevistas realizadas, observaciones de campo e informes de amigos de aquellos lares, se registra que la mitad de los informantes leían la biblia o asistían a reuniones donde ésta se leía -muchos de los entrevistados no saben leer. Circulan distintas ediciones de la biblia; hay varias "biblias" y, de ellas las que tuve a la mano ninguna era católica. Empero, haría falta hacer un estudio cuidadoso de ellas y de la interpretación que cada organización pueda darle a la que consulta. Por otra parte, los informantes dijeron escuchar más música ranchera y radio-novelas que programas religiosos y, de entre éstos, más de los "hermanos" que de los "curas". Hay biblias como programas radiofónicos en lenguas locales, lo que permite una comunicación más directa entre emisor y receptor; sin duda esto contribuye al creciente éxito en el proselitismo de los mensajes protestantes y de disidencia no protestante. ${ }^{6}$

La presencia y actividades de los protestantes y de disidentes no protestantes, en algunas localidades han incidido en conflictos locales, pero en otras se presenta una tolerante convivencia. Recuérdese que se está hablando de una población histórica y predominantemente católica; de ahí que la posterior llegada de otras organizaciones cristianas irrumpa en los espacios religiosos y sociales preestablecidos; particularmente en los caseríos alejados, el nivel de conflicto socio-religioso es mínimo. Hay una convivencia con ciertas fricciones entre familiares, amigos y vecinos cuando la insistencia proselitista les llena la cabeza; esto en algunas localidades menores,

${ }^{6}$ También, sobre este tema, hace falta una investigación especializada. 
porque en otros, la gente decía simplemente "aquí no hay problema". En principio podría decirse que hasta ahora, en algunas pequeñas localidades, las diferencias religiosas no significan necesariamente una inestabilidad social. Incluso se puede decir que, hasta ahora, esta afirmación es válida para la mayoría de las poblaciones chiapanecas. Si esto no fuera así, tendríamos una inestabilidad generalizada, aparentemente por motivos religiosos, que ya hubiera reclamado una enérgica y pública acción por parte de las autoridades gubernamentales, tanto de la entidad como federales. Y, hasta donde se sabe, esto no ocurre así. Lo anterior no significa que no se den conflictos sociales por aparentes causas religiosas; ${ }^{7}$ por supuesto que los hay, algunos muy conocidos como los de San Juan Chamula, en donde se calcula que aproximadamente un $10 \%$ de la población nacida en dicho municipio ha sido expulsada por su conversión religiosa al protestantismo o a la disidencia no protestante, y que las expulsiones continúan. Es decir, estamos hablando de un promedio de diez mil personas expulsadas hasta fecha reciente. En los parajes a donde se han ido a vivir los expulsados, en algunos lugares se dan casos de convivencia de evangélicos presbiterianos, pentecostales, testigos y adventistas y uno que otro católico; en otros, se reproduce la intolerancia religiosa, donde algunos expulsados son objetos de una segunda expulsión luego de querer establecer o de establecer de hecho una organización religiosa diferente. Esto significa que no hay un comportamiento único, de ahí la necesidad de los estudios de casos. Otros pueblos, como Chenalhó y Larrainzar, también en la zona tzotzil de los Altos de Chiapas, viven serios problemas de naturaleza político-religiosa. Lo común a los tres casos citados es la mezcla de problemas de tierras, de reparto y cumplimiento de los cargos tradicionales, de celebración de las festividades del patrono del pueblo, de la venta y consumo de bebidas embriagantes y cigarros, etc., en donde los poderes constituídos, incluyendo la iglesia católica, ya tienen una manera acordada de cómo hacer las cosas. Quienes disienten en estas sociedades tradicionales, lo hacen en todos los campos, pues ahí todos forman un todo indiferenciado, en consecuencia rompen los campos sociales y religiososy, lo más grave e intolerable para la gente de poder, es que se atenta

\footnotetext{
${ }^{7}$ No se descarta la posibilidad teórica de que se den conflictos estrictamente por motivos religiosos; sin embargo, hasta el momento no he encontradoen Chiapas alguno que pueda catalogarse como tal.
} 
directamente contra la estructura de dominación. De ahí la expulsión necesaria de los disidentes para preservar el orden establecido, la paz social "aceptada".

Pero también se dan otrasformas de solución, como en Tapachula. Ahíse presenta un conflicto político-religioso aunque de características diferentes. Gente del lugar comenta que el principal líder agrario regional, de la Confederación Nacional Campesina $(\mathrm{CNC})$, residente en Tapachula, se convirtió al protestantismo. El problema se presentó en vísperas de las elecciones municipales, cuando en su organización confesional se discutió y acordó apoyar activamente la candidatura panista; el líder se opuso y antes del acuerdo final, amenazó con salirse de la secta si no se acordaba apoyar al candidato del Partido Revolucionario Institucional (PRI). Como su amenza no prosperó, los lugareños dicen que formó su propia secta, así que había la secta del PRI y la secta del Partido Acción Nacional (PAN). Todavía en 1988, el otrora candidato priísta despacha desde el palacio municipal. Las sectas, por su parte, siguen activas y a veces uno encuentra grupos de ellas en la plaza principal, a escasos metros del palacio, en actos públicos de proselitismo religioso. Tal parece que, obviando la norma constitucional, se ha encontrado una vía de acuerdo y colaboración partidaria.

Por otra parte, son reiterados los señalamientos de que las organizaciones protestantes y de disidencia no protestante difunden valores individualistas, antisociales, proimperialistas, milenaristas, antinacionales, etc. La crítica va dirigida particularmente a los grupos disidentes no protestantes tales como los testigos de Jehová, adventistas del séptimo díay otras organizaciones fundamentalistas. Aunque no hay un estudio de caso de lo que ocurre en México que dé una respuesta fundamentada y permita hacer las distinciones pertinentes, lo cierto es que los pocos trabajos pioneros que se han hecho sobre el particular en Chiapas, las denuncias en la prensa y las opiniones de la gente entrevistada, al menos para los casos citados, coinciden en señalar que los grupos disidentes referidos son los que más se distinguen por ser los que irrumpen el orden social existente localmente. Irrumpen en el sentido de que desestimulan el involucramiento de sus fieles en la organización, toma de decisiones y/o ejecución de obras de utilidad comunal, así como la no participación de los hijos de los fieles 
en las ceremonias a los símbolos patrios. ${ }^{8}$ Mas hay que tener cuidado con quién, cómo, por qué y cuándo lo dicen, pues como hemos visto, no es posible señalar un comportamiento social único, válido para todas las organizaciones protestantes o disidentes no cristianas. De ahí la urgente necesidad, por un lado, de efectuar estudios de caso y, por el otro, de tomar con carácter de hipotético el señalamiento de tendencias, a las cuales se les dedicará unas líneas en un momento más.

En otro orden de ideas, se anota un comentario sobre aspectos ideológicos tomando como punto de referencia a los testigos de Jehová, ya que en Chiapas los testigos son los que más han ensanchado su base poblacional y son señalados como los principales irruptores sociales. Fundamentalmente se toma comobase un estudioque se hizo en Cuba publicado en 1977 con el nombre de La verdad sobre la secta testigos de Jehová, y en menor medida en el trabajo de Erwin Rodríguez Un evangelio según la clase dominante publicado por la UNAM en 1982; el primero hace la transcripción de largos párrafos de diversas publicaciones de los testigos, las historias de vida que presenta y sus narraciones sobre los comportamientos sociales respecto de los símbolos patrios, actividades comunales, sumisión al orden capitalista y de intolerancia hacia los movimientos sociales de corte socialista y países con ese régimen, el ensalzar el american way of life, etc., coinciden con los tipos de mensaje de los volantes que compiló Rodríguez en Tapachula en 1979 y con lo dicho en ejemplares de $L a$ atalaya que actualmente circulan en la región chiapaneca. Estas coincidencias en espacio y tiempo alientan la preocupación de que en Chiapas, hoy en día, los testigos difunden ciertos valores sociales y con ropaje religioso que han sido y son comunes en su significado ideológico: la defensa de un determinado capitalismo norteamericano. Nuevamente, debe hacerse un reconocimiento de honestidad intelectual: no se cuenta con una base ampliamente documentada para decir

\footnotetext{
${ }^{8}$ Negativa que, vale decir, la practican en todos los países del mundo en que se encuentran fieles de dichas organizaciones. Esto incluye a los Estados Unidos, sin que se sepa que el nacionalismo en dicho país oel respeto nacional al lábaro patrio hubieran desaparecido. Con ello quiero decir que los alarmismos no ayudan a la explicación y sólo desatan cacerías de brujas. En todo caso, hace falta un estudio de cultura política que considere el fenómeno religioso.
} 
que todos los testigos son de este corte, pero las pocas evidencias permiten señalar una tendencia, de donde se sigue una exploración hipotética sobre lo real y lo posible.

Es indudable el crecimientoy las actividades de las organizaciones protestantes y de los grupos disidentes noprotestantes, en particular de los testigos de Jehová, seguidos por adventistas y organizaciones pentecostales. El fenómeno se presenta plural y complejo, dada la diversidad de denominación de las organizaciones que puede uno encontrar y las diferencias que se pueden llegar a establecer entre sus concepciones y prácticas sociales. No puede negarse que, entre los grupos subalternos, algunos se han convertido en vehículos de expresión de sus inconformidades sociales; sean como refugios de fe que los aisle de la problemática social y alimente en ellos la inminente venida del Mesías, es decir, la esperanza milenaria-y, atención, estamos a fin de siglo y de milenio-; sean también, como formas orgánicas que permitan el reconocimiento y el ascenso social en su entornoinmediato, por vías distintas al tradicional sistema de cargos, oneroso y viciado; el carisma personal (Cfr. Weber, 1987) es fundamental para el pastor (el don de lenguas y el don de curar, pues provoca un trato diferente, tomándose como distinciones divinas). Complementariamente, la colectividad que se nuclea bajo un mismo signo de fe, en su práctica cotidiana y convivencia en torno a lo sagrado en número reducido, les genera un sentimiento de identidad y pertenencia que no se produce de igual forma en la masa social (Garma 1988: 89-99). En pocas palabras, las nuevas asociaciones religiosas en el corto plazo han ofrecido respuestas a demandas sociales de dichas colectividades, pues no hay que olvidar que, en primer lugar, su emergencia se explica como reacción a condiciones económicas, políticas, sociales y culturales, más que a una disidencia cismática católica o cristiana (Cfr. Valderrey 1988). Sin embargo, no por ver el corto plazo puede dejarse de lado el mediano y largo plazos. Su presencia atomizada no es necesariamente anárquica como pudiera parecer, al menos no en todos los casos. A mayor elaboración y énfasis en determinados valores socioreligiosos se puede lograr una articulación específica. Esto, me parece, es una característica particular de los grupos disidentes no protestantes. No es que los protestantes no tengan un mensaje 
social; de hecho toda religión, al actuar en sociedad, no puede abstraerse a ella, aunque a nivel ideológico señale lo contrario?.

Mas en el caso de los disidentes no protestantes uno encuentra un énfasis mayor en determinados valores sociales, lo que permite hipotetizar que ahí es donde se da su principal articulación y que mediante el éxito que puedan lograr con esos valores influyen en los derroteros de la sociedad y como dichos valores son polémicos, por llamarlos así, se exploran sus implicaciones.

Habría, entonces, una relación entre una práctica socio-religiosa local con una internacional, es decir, la práctica local no sería un hecho aislado del resto del mundo. Con este no digo que entre los testigos -por seguir citando el caso más llamativo- de una localidad por ahí perdida, tengan conciencia de complot internacional, pero sí digo que en su práctica socio-religiosa reproducen cotidianamente una cosmovisión determinada que es, a final de cuentas, un refuerzo a un sistema social específico y a una ideología acorde con dicho sistema.

Si ello fuera así, estaríamos frente a una toma de posiciones en el conflicto Este-Oeste, aunque en una trinchera con camuflaje religioso y, para utilizar una terminología gramsciana, insertos en una guerra de posiciones. En efecto, recuérdese que Chiapas es frontera con Centroamérica, también recuérdese que desde el triunfo de la revolución cubana han resurgido con nuevos bríos las insurgencias populares en el área, los planes estadounidenses de "ayuda" económica y militar a sus gobiernos amigos y, casualmente, el principio de un ensanchamiento de labase poblacional protestante en Chiapas, como vimos con anterioridad ${ }^{10}$.

En estos tiempos en que laguerra mal encubierta sigue en América Central y se acrecentan los flujos de migrantes hacia el norte del

9 Y esto es válido para todas las organizaciones religiosas, incluida la católica. De ahí que diga que es necesario abordar con sumo cuidado lo referente a los valores sociales que conllevan los mensajes religiosos, pues en sentido estricto, ninguno de los cristianos, cristianos católicos y disidentes no cristianos, están exentos de aportaciones, de pensamiento y obra externos. Mas, no por ello, deben desatarse las fobias xenofóbicas. Importa analizar y, en todo caso, tomar una postura definida sobre su actuación y compromiso social.

${ }^{10}$ Los censos de población no señalan distingos entre protestantes ydisidentes no protestantes, entre "pastorales" y "politizantes". 
continente, los estados nacionales tienden a cerrar sus fronteras o a intentar ser más estrictos en su control sobre ellas. Asílo hacen Estados Unidos y México, respectivamente, en la actualidad.

Una "colaboración" de la población civil contraria a cualquier movimiento social que se le identifique comosocializante no cae mal para evitar el "contagio centroamericano". Pero esto no lo debiera permitir un Estado tan celoso de preservar su coto de caza, como es el Estado mexicano. Y no lo debiera permitir por muchas coincidencias que pudiera haber entre ciertos sectores gubernamentales con ese enfoque del contagio, y que de ir concretizando sus coincidencias no sólo se fortalecería un eventual trastocamiento de una política exterior pacifista y solidaria con los desplazados de la guerra, sino también tendría sus repercusiones internas.

Chiapas es una entidad con viejos problemas de tenencia de la tierra y de antidemocracia -entre otros-, sus grupos de poder son cerrados y reacios a ampliar el juego político -que ampliarlo no necesariamente significa democracia-y a afectar la estructura económica- que hacerlo tampoco significa necesariamente la desaparición de la propiedad privada. En pocas palabras, para ellos una modernización capitalista es una especie de socialismo disfrazado. Desde esta óptica, las expresiones religiosas de los conflictos sociales internos se pueden presentar y de hecho se han presentado, como producto exclusivo de las diferencias confesionales; al desarticular la discrepancia religiosa, de paso se pretende desarticular la inconformidad social. Si esto preserva el orden social preestablecido puede pensarse que hay continuidad en la estabilidad social o incluso puede pensarse, pragmáticamente, que la creencia y práctica religiosa, al darle voz a los sin voz, sirve porque organiza y resuelve algunos problemas locales de dimensiones menores.

El problema está en que este tipo de lecturas, que ya se han hecho en otras ocasiones, refuerza los compromisos del Estado federal con los grupos de poder local; si bien es cierto que esa es la base histórica del Estado mexicano, también es cierto que dicha base cada vez es menos suficiente y sostenible, tal cual, con el discurso revolucionario y oficial de democracia, justicia y legitimidad gubernamentales. En esta lógica, con la creciente acción política de algunas organizaciones religiosas, con la continuada conflictividad centroamericana, con los 
crecientes flujos de llegada y de paso de migrantes de esa área, con los compromisos existentes con los grupos de poder local, con los reclamos populares de solución a la crisis económica y política, etc., lo cual en conjunto presenta innumerables contradicciones, el Estado mexicano enfrenta una situación compleja y no de fácil solución. De hecho, no se puede esperar de él soluciones de fondo e inmediatas; se puede esperar que no se abra a tantos frentes de manera simultánea como de hecho, hay que reconocer, está intentando no hacerlo- ni dejar crecer problemas que a la vuelta de los años se le vuelvan inmanejables. Lo que ocurre actualmente con algunos organismos confesionales como aquí lo hemos visto, reclama un estudio serio e inmediato, general y con investigaciones de caso. En este sentido tranquiliza saber, como se indicó al principio de este ensayo, que ya el Estado acordó patrocinar unos primeros estudios sobre el fenómeno religioso. Ojalá que pronto todos sepamos de ellos, que no sólo reciban el imperturbable juicio de los archivos, o que queden inconclusos por fin orecorte de presupuesto, por la obligada austeridad gubernamental para algunos rubros sociales. También esperemos que la sociedad, mediante distintas instancias sociales y académicas, haga su aportación y genere las nuevas condiciones necesarias que garanticen la vida pública de las asociaciones religiosas, la tolerancia social y la preservación de los derechos fundamentales de los mexicanos y residentes en el país. 


\section{B I B L I O G R A F I A}

BASTIAN, Jean Pierre. Breve historia del protestantismo en América Latina. México, CUPSA. 1986.

BASTIAN, Jean Pierre. Protestantismo y sociedad en México. México, CUPSA. 1983. Constitución Política de los Estados Unidos Mexicanos. México. Ed. Porrúa. 1987. 82a. ed.

GARMA, Carlos. "Liderazgo, mensaje religioso y contexto social". En Cristianismo y sociedad. XXVI/1 No.95. México. ASEL, 1988.

PORTELLI, Hugues. 1977. Gramsci y la cuestión religiosa. Barcelona. Ed. Laia.

VALDERREY, José. "Los nuevos movimientos religiosos a nivel mundial y latinoamericano". Ponencia presentada a la Conferencia Episcopal Mexicana. México. Abril de 1988, mimeo.

VIII Censo General de Población y Vivienda. Dirección General de Estadística. Secretaría de Industria y Comercio. México, 1964.

IX Censo General de Población. Dirección General de Estadística. Secretaría de Industria y Comercio. México, D.F. 1971.

$X$ Censo General de Población y Vivienda. Instituto Nacional de Estadística, Geografía e Informática, S.P.P. México. 1984. 